\title{
Socioeconomic position and cardiovascular mortality in 63 million adults from Brazil
}

Poppy Alice Carson Mallinson $\mathrm{MSc}^{1 *}$, Shammi Luhar $\mathrm{PhD}^{1,2}$, Elizabeth Williamson $\mathrm{PhD}^{1}$, Mauricio L. Barreto MD PhD ${ }^{3,4}$, Sanjay Kinra MD PhD ${ }^{1}$

${ }^{1}$ Faculty of Epidemiology and Population Health, London School of Hygiene \& Tropical Medicine, London, United Kingdom

${ }^{2}$ Department of Public Health and Primary Care, University of Cambridge, Cambridge, UK ${ }^{3}$ Centre for Data and Knowledge Integration for Health (CIDACS), Fundação Osvaldo Cruz, Salvador, Brazil

${ }^{4}$ Institute of Collective Health, Federal University of Bahia, Salvador, Brazil

*Corresponding author. Contact: poppy.mallinson1@Ishtm.ac.uk, +447875866640, London School of Hygiene and Tropical Medicine, Keppel Street, London, WC1E 7HT, UK.

The Corresponding Author has the right to grant on behalf of all authors and does grant on behalf of all authors, an exclusive licence on a worldwide basis to the BMJ Publishing Group Ltd and its Licensees to permit this article (if accepted) to be published in HEART editions and any other BMJPGL products to exploit all subsidiary rights.

Manuscript word count: 2988 


\section{ABSTRACT}

Background: It has been suggested that cardiovascular disease exhibits a 'social crossover', from greater risk in higher socioeconomic groups to lower socioeconomic groups, on economic development, but robust evidence is lacking. We used standardised data to compare the social inequalities in cardiovascular mortality across states at varying levels of economic development in Brazil.

Methods: We used national census and mortality data from 2010. We used age-adjusted multilevel Poisson regression to estimate the association between educational status and cardiovascular mortality by state-level economic development (assessed by quintiles of Human Development Index).

Results: In 2010, there were 185,383 cardiovascular deaths among 62.5 million adults whose data were analysed. The age-adjusted cardiovascular mortality rate ratio for women with $<8$ years of education (compared to $8+$ years) was 3.75 (95\% confidence interval $(\mathrm{Cl})$ $3.29,4.28)$ in the least developed one-fifth of states, and $2.84(95 \% \mathrm{Cl} 2.75,2.92)$ in the most developed one-fifth of states ( $p$-value for linear trend=0.002). Among men, corresponding rate ratios were $2.53(95 \% \mathrm{Cl} 2.32,2.77)$ and $2.26(95 \% \mathrm{Cl} 2.20,2.31)$, respectively (pvalue $=0.258$ ). Associations were similar across subtypes of cardiovascular disease (ischaemic heart disease and stroke) and robust to the size of geographical unit used for analysis.

Conclusions: Our results do not support a 'social cross-over' in cardiovascular mortality on economic development. Our analyses, based on a large standardised dataset from a country that is currently experiencing economic transition, provide strong evidence that low socioeconomic groups experience the highest risk of cardiovascular disease, irrespective of the stage of national economic development.

Keywords: cardiovascular; Brazil; economic development; mortality; socioeconomic position. 


\section{KEY QUESTIONS}

What is already known about this subject?

It is often assumed that socioeconomic inequalities in cardiovascular mortality exhibit a 'cross-over', from greater risk in high socioeconomic groups, to greater risk in the low socioeconomic groups, upon economic development; however, there is limited evidence to support this claim.

What does this study add?

Our data comparing states of Brazil at different levels of economic development suggest that lower socioeconomic groups may experience the highest cardiovascular mortality irrespective of a country's stage of economic development.

How might this impact on clinical practice?

The belief that low socioeconomic groups are initially at less risk of cardiovascular mortality compared to high socioeconomic groups is not substantiated, and risks preventing appropriate targeting of policies in low- and middle-income countries, which could further exacerbate inequalities. 


\section{MANUSCRIPT}

\section{INTRODUCTION}

Research suggests that cardiovascular disease (CVD) exhibits a social cross-over, from greater risk in higher socio-economic groups to lower socio-economic groups, on economic development.(1-4) However, historical evidence supporting this hypothesis from highincome countries (HICs) has been called into question, $(5,6)$ while comparisons of countries at different levels of economic development have reported inconsistent findings, potentially due to systematic differences in data sources and quality.(7-10) Linked temporal data on social position and cause-specific mortality are lacking for most low- and middle-income countries (LMICs). Many highly-populated LMICs that are currently experiencing economic transition exhibit considerable sub-national variation in levels of economic development, which could be utilised as counterfactuals to address this hypothesis using cross-sectional data.

Brazil is middle-income country of 200 million people, with levels of economic development ranging from that of some lower middle- to upper middle-income countries across her 26 states. CVD is the leading cause of death in Brazil, with trends comparable to other LMICs.(11) Brazil's standardised national data and universal healthcare, provides a unique opportunity to simultaneously examine the association between socioeconomic position and cardiovascular mortality across different levels of economic development, while minimising potential bias from other factors which vary between countries. We used national census and mortality data to assess the association between education and cardiovascular mortality between the economically diverse states of Brazil, hypothesising a positive association between socioeconomic position and cardiovascular mortality in less developed states and the opposite association in more developed states, consistent with a change in the association on economic development.

\section{METHODS}


We conducted a cross-sectional study using routinely collected mortality and census data, which are available online on Brazilian government websites.(12,13) Data on age, sex, education and municipality of residence were available from both data sources. Deaths are notifiable in Brazil, with coverage of mortality registration estimated to be over $95 \%$ in 2010.(14) For both data sources, we used data from 2010, as this was the most recent year for which accurate census data were available. (15)

We identified cardiovascular deaths using ICD-10 codes 100-99. We also examined CVD subtypes ischaemic heart disease (IHD) and stroke (using ICD-10 codes I20-25 and I60-69 respectively), as literature suggests that the social-crossover between socioeconomic position and cardiovascular mortality is driven largely by IHD.(16) We examined overall, as well as premature, cardiovascular mortality (defined as deaths under age 70), as recommended in the World Health Organisation's Non-Communicable Disease Global Monitoring Framework.

Socioeconomic position was defined by number of completed years of education. Education captures multiple dimensions of socioeconomic position relevant to CVD, including relative social status, earning potential and health-related knowledge.(17) Education in Brazil follows the same grading system across all states as it is delivered federally. In 2010 , the education categories on death certificates were: $0,1-3,4-7,8-11$ and 12 or more years of education completed; and on census were: none, creche/pre-school, elementary school, high school (and subcategories of these), graduate, masters, and doctorate. To minimise potential misclassification of education between the two data sources, we categorised education into two broad groups (<8 vs $8+$ years of education completed, corresponding to did not vs did complete elementary school).

We classified state-level economic development using Human Development Index (HDI), a composite measure combining education, health and economic productivity as it captures a broader range of economic indicators than solely income-based metrics. 
Statistical analyses

The final aggregated dataset contained, for every unique combination of variables, data on the person-years at risk in 2010 (approximated by mid-year population size) and the number of CVD deaths in 2010.

We restricted the study population to adults aged over 20 years, as CVD rarely affects children and adolescents. As the quality of mortality reporting varies across Brazil,(14) we derived an indicator for high coverage of mortality registration for each municipality by comparing the number of deaths reported in the 2010 census(18) to the number of deaths in the mortality registry over the same period. We included municipalities for which agreement between deaths in the mortality registry and census was of a comparable level to states known to have near-complete mortality registration (ratio of registry to census deaths of 21.08). To assess the sensitivity of results to this choice of indicator, we also repeated the analyses using data from all municipalities. As three states (Roraima, Acre and Amapá) were too small to be analysed individually, they were merged with their most similar neighbour, resulting in 23 geographical units (hereafter referred to as states). We also repeated the analyses stratifying by the five regions of Brazil (North, North-east, Centrewest, South, South-east).

We modelled cardiovascular mortality count using age-adjusted multilevel Poisson regressions to compare mortality between people with $<8$ vs $8+$ years of education. To capture the non-linear relationship between age and mortality, in addition to age we adjusted for age-squared and age-cubed, both of which significantly improved the model fit. Personyears at risk was included as an offset term. We included state-level and municipality-level random intercepts to account for geographical clustering of cardiovascular mortality, and additionally allowed the association with education to vary randomly across states. To assess for systematic variation in the association between education and cardiovascular mortality by state-level HDI we included an interaction term between these variables, with HDI considered as a categorical (splitting the 23 states into quintiles according to their HDI), 
and then a continuous measure. Interaction terms for gender were also included in all models.

We used multiple imputation with chained equations to minimise the potential for bias due to missing data on education ( $20 \%)$ and ill-defined causes of death ( $8 \%$ of deaths, considering ICD-10 garbage codes R00-R99 to be "missing") in the mortality registry (see Methods S1).

Ethical approval was not obtained as this study used only de-identified secondary data available in the public domain.

\section{RESULTS}

In 2010 , there were 185,383 reported cardiovascular deaths among $62,568,055$ adults included in the study (49\% of all Brazilian adults). Our primary analyses were restricted to municipalities with high mortality registration (2004 out of 5565 municipalities). The excluded population were more likely to live in the less economically developed regions of Brazil, and were less likely to be educated. Cardiovascular mortality was lower among the excluded population, as expected due to the lower mortality registration in excluded municipalities. Sizes of the included and excluded population, and differences between them, are given in the Supplemental Material (Table S1 and Table S2).

The crude cardiovascular mortality rate in Brazil was 296 per 100,000. After adjusting for age, cardiovascular mortality was over twice as high in men with $<8$ years education compared to $8+$ years education, and nearly three times higher in women with $<8$ years education compared to $8+$ years education (Table 1 ).

(Table 1 here)

$\mathrm{HDI}$ of the states ranged from 0.63 to 0.78 . We observed an inverse association between education and cardiovascular mortality in states of Brazil across all levels of economic development, but with considerable subnational variation (Figure 1). Among women, higher 
state-level HDI was associated with a lower rate ratio for education $(P$-value for log-linear trend $=0.002)$, whereas this trend was less pronounced among men $(P=0.258)($ Table 2$)$. For example, the age-adjusted cardiovascular mortality rate ratio for women with $<8$ years of education (compared to $8+$ years) was $3.75(95 \% \mathrm{Cl}: 3.29,4.28)$ in the least developed quintile of states and $2.84(2.75,2.92)$ in the most developed quintile. The age-adjusted cardiovascular mortality rate ratio for men with $<8$ years of education (compared to $8+$ years) was $2.53(2.32,2.77)$ in the least developed quintile and $2.26(2.20,2.31)$ in the most developed quintile (Table 2). For IHD and stroke mortality we observed an inverse association with educational status in all states, and among women, higher state-level HDI was associated with lower rate ratios (although confidence intervals suggested no linear trend by HDI). For IHD among men, there was some suggestion of a non-linear association, with the highest rate ratios for education observed in the lowest and highest HDI states. Restricting the analyses to 'premature' cardiovascular deaths (age $<70$ years) did not substantively alter the results.

(Figure 1 here)

(Table 2 here)

As a sensitivity analysis, we repeated the analyses using all municipalities ( $n=5565$, population=127,826,740), and found similar results (Table S3). Our results were also robust to use of region $(n=5)$ instead of state as the geographical unit of analysis (Table S4).

\section{DISCUSSION}

We found that lower educational status was associated with higher cardiovascular mortality in both more and less economically developed states of Brazil. Among women, these social inequalities in cardiovascular mortality were larger in the less economically developed states. Associations were robust to use of different geographical units of analysis and different inclusion criteria for data quality. Thus, we find no evidence to support a 'social 
cross-over' in CVD mortality, from greater risk in higher socioeconomic groups to greater risk in lower socioeconomic groups, on economic development in a large middle-income country.

The phenomenon of a 'social cross-over' in CVD on economic development is frequently cited in the global health literature.(1-4) Historical data from the UK demonstrated a change in the association between occupational social class and non-valvular heart disease mortality from positive to inverse between 1951 and 1971.(5) However subsequent reanalysis of this data suggested the apparent 'cross-over' may have been an artefact of bias in mortality coding practices (deaths among low socioeconomic groups were less likely to be attributed to IHD).(6) A review of studies from the UK and US between 1930 and 1960 which measured IHD objectively found a null or inverse association in 11 out of 12 studies.(6) An ecological study from Hong Kong reported a change in the association between neighbourhood median income and cardiovascular mortality from positive to inverse between 1976 and 1995, but this 'cross-over', is unlikely to be attributable to economic development as Hong Kong was relatively economically advanced throughout this period.(19) Long term data from a demographic surveillance site in Bangladesh reported that household wealth was positively associated with IHD mortality in 1983, and not associated in 2005, although the tenfold increase in IHD mortality between surveys (presumably due to the high proportion of unassigned deaths in earlier surveys) suggests that this data could not be reliably compared over time.(20)

By comparing areas at varying levels of economic development at one point in time to investigate a 'social cross-over' in cardiovascular mortality on economic development, we avoided potential biases related to systematic changes in cardiovascular mortality coding practices and data quality over time. A few other studies have compared social inequalities in CVD across countries at different levels of economic development, and generally found an inverse association in high- as well as low/middle-income countries.(7-10) However all of these studies except one(10) combined LMICs into a single category, and did not examine variation in the association by stage of economic development, which could have provided 
more relevant evidence for the 'social cross-over' hypothesis given that the inverse association in HICs is well-established.(16) A recent prospective study of 20 low- to HICs found that inverse associations between socioeconomic position and incident CVD were stronger in low-income than middle-income countries, consistent with our findings and inconsistent with the 'social cross-over' hypothesis.(10)

Explanations for a 'social cross-over' in CVD generally refer to changes in the socioeconomic patterning of cardiovascular risk behaviours. An important factor in HICs may have been the shift in smoking from high to low socioeconomic groups around mid-20 ${ }^{\text {th }}$ century, $(5,16)$ although there is no evidence to support a similar shift in LMICs. (21) More relevant to LMICs may be the replacement of occupational physical activity among low socioeconomic groups in pre-industrialised economies by leisure-based physical activity among high socioeconomic groups in industrialised economies, and the increasing availability of low-quality, calorie dense diets.(5) Accordingly, many middle-income countries are experiencing dramatic increases in obesity prevalence, especially among lowsocioeconomic groups.(22) While it seems plausible that a 'social cross-over' in diet, activity and obesity might explain a similar 'cross-over' in cardiovascular mortality, data from LMICs do not support this. For example in India, socioeconomic position is associated positively with overweight/obesity(23) but inversely with cardiovascular mortality;(10) if a 'social crossover' in cardiovascular mortality had already occurred in India, it would have preceded a 'social cross-over' in obesity, and thus could not have been caused by it. However it is possible that an earlier 'social cross-over' in obesity among women compared with men, observed in many countries including Brazil, contributes to the gender differences in inequalities in cardiovascular mortality that we observed(22,24).

The lack of plausible mechanisms to account for a 'social cross-over' in cardiovascular mortality is consistent with our findings from Brazil of greater cardiovascular mortality in low socioeconomic groups, irrespective of state-level economic development. Reasons for greater cardiovascular mortality in low socioeconomic groups in LMICs may be similar to 
those in HICs, for example reduced access to health services,(10) exposure to harmful environmental conditions (e.g. air pollution and occupational hazards), increased smoking rates,(21) and diet lower in fruits and vegetables.(10) Novel and unestablished risk factors, such as early life undernutrition, frequent infections and psychosocial adversity, could play an important role in LMICs, warranting further research in these settings.

We used an innovative study design to circumvent the lack of high-quality temporal data on social inequalities in cardiovascular mortality from LMICs. The large population sizes (ranging from 1.5 to 45 million) and diversity in economic development (encompassing levels of HDI comparable to lower middle-income (e.g. Bangladesh and Honduras) and upper middle-income (e.g. Mexico and Albania) countries) in Brazilian states allowed us to use them as counterfactuals to investigate the change in social inequalities on economic development, while controlling for bias from other factors that vary between countries or within countries over time (e.g. data quality and health-system factors). Furthermore, our use of national routine data allowed us to precisely estimate inequalities across a large number of geographical units.

However, the study also has some limitations. We used a single transitioning country to test a generalisable hypothesis, but each country is likely to have its own setting-specific factors that modify trends in social inequalities in CVD. For example, in Brazil, there was an expansion of primary care services and other progressive social reforms from the mid-1990s onwards, which may have resulted in an underestimation of the inverse associations noted in even the least developed states.(26) The non-linear trends in social inequalities we observed among men for some outcomes warrant further exploration, as they suggest a potential role for setting-specific differences between the states. Furthermore, the Brazilian states included in our analyses were comparable to lower- and upper-middle income countries, but the results may not be generalisable to countries outside this range of economic development. Supportive data from countries at extremely low levels of economic development are needed. 
The coverage and quality of mortality reporting was variable across states, which could have introduced some potential for bias. Firstly, there was more under-registration of deaths in the lower HDI states.(27) To minimise the potential bias arising from this, we restricted our analyses to municipalities with high mortality registration using a robust indicator based on an independent data source.(18) The socio-demographic characteristics of the included and excluded populations were similar, and the results hardly changed when we included the whole population in sensitivity analyses (Table S2 and Table S3). Secondly, a greater proportion of causes of deaths were ill-defined in the lower HDI states. Although we used multiple imputation to account for this, multiple imputation assumes that the data were missing-at-random, which may not have been the case. In Brazil, ill-defined causes of death are more common in populations with reduced access to medical facilities (e.g. rural populations), while CVDs are over-represented among the ill-defined causes of death $(27,28)$. However, we expect that any residual bias due to mortality under-reporting or ill-defined causes of death would under-estimate the inequalities in cardiovascular mortality in lower HDI states, suggesting that, if anything, our conclusions are likely to be conservative.

It is possible that there was some misclassification of educational status in the census or, more likely, on the death certificates (which are usually completed by the attending physician). This could potentially introduce numerator-denominator bias, a bias which arises when covariates used to link numerators to denominators are misclassified. The extent or direction of numerator-denominator bias is difficult to predict; however, the social inequalities for IHD mortality in our study were comparable to those for prevalent disease reported in another nationally representative survey, providing face-validity to our results.(29) Our use of a binary categorisation for education will have helped to reduce misclassification and achieve a more valid match between education categories on the death certificate and census. Furthermore, education has been shown to be less prone to numerator-denominator bias compared to other socioeconomic indicators such as occupation and income, and does 
not change with age among older adults, making it particularly suitable for adult mortality studies. $(17,30)$

Another potential limitation is that we used HDI to classify the level of development of the states, which incorporates life expectancy and thus may be influenced by the outcome of cardiovascular mortality. Lower HDI states will tend to have higher mortality rates (including cardiovascular), leading to smaller relative inequalities in mortality in these states(11).

Similar to the other potential biases discussed above, this may have led to an underestimation of social inequalities in cardiovascular mortality in lower HDI states, suggesting our conclusions could be conservative.

The belief in a 'social cross-over' in CVD mortality on economic development, from greater risk in high socioeconomic groups to greater risk in low socioeconomic groups, is not supported by evidence from LMICs. We urge caution when referring to this phenomenon, as doing so risks propagating a misrepresentation of social inequalities in CVD in LMICs. Our analysis provides strong evidence that low socioeconomic groups experience the highest cardiovascular mortality irrespective of stage of economic development. There is a need for high-quality prospective data from LMICs to describe and elucidate mechanisms of these social inequalities in CVD. Policies for the control of CVD and its risk factors in LMICs must be inclusive of low socioeconomic groups. 


\section{ACKNOWLEDGEMENTS AND AFFILIATIONS}

Funding: This work was funded by Medical Research Council UK (grant number: MR/N013638/1) through a studentship to PACM.

Authors' Contributions: PACM and SK conceived the study. PACM conducted data management and analyses, and wrote the first draft. EW provided statistical support. SL, EW, MLB and SK reviewed and commented on all drafts of the manuscript.

Patient and public involvement: Patients or the public were not involved in the design, or conduct, or reporting, or dissemination plans of our research.

Declarations of interest: We declare no competing interests.

Ethical approval: Ethical approval was not obtained as this study used only de-identified secondary data available in the public domain. 


\section{REFERENCES}

1. Clark AM, DesMeules M, Luo W, Duncan AS, Wielgosz A. Socioeconomic status and cardiovascular disease: risks and implications for care. Nat Rev Cardiol. 2009 Nov;6(11):712-22.

2. Reddy KS. Cardiovascular Disease in Non-Western Countries. N Engl J Med. 2004 Jun 10;350(24):2438-40.

3. Niessen LW, Mohan D, Akuoku JK, Mirelman AJ, Ahmed S, Koehlmoos TP, et al. Tackling socioeconomic inequalities and non-communicable diseases in low-income and middle-income countries under the Sustainable Development agenda. The Lancet. 2018 May 19;391(10134):2036-46.

4. Miranda JJ, Barrientos-Gutiérrez T, Corvalan C, Hyder AA, Lazo-Porras M, Oni T, et al. Understanding the rise of cardiometabolic diseases in low- and middle-income countries. Nat Med. 2019;25(11):1667-79.

5. Marmot MG, Adelstein AM, Robinson N, Rose GA. Changing social-class distribution of heart disease. Br Med J. 1978 Oct 21;2(6145):1109-12.

6. Davey Smith G, Lynch J. Socioeconomic differentials. In: A Life Course Approach to Chronic Disease Epidemiology. 1st edition. Oxford: Oxford University Press; 1997. p. 242-73.

7. Manrique-Garcia E, Sidorchuk A, Hallqvist J, Moradi T. Socioeconomic position and incidence of acute myocardial infarction: a meta-analysis. J Epidemiol Community Health. 2011 Apr 1;65(4):301-9.

8. Rosengren A, Subramanian SV, Islam S, Chow CK, Avezum A, Kazmi K, et al. Education and risk for acute myocardial infarction in 52 high, middle and low-income countries: INTERHEART case-control study. Heart. 2009 Dec 15;95(24):2014-22.

9. Goyal A, Bhatt DL, Steg PG, Gersh BJ, Alberts MJ, Ohman EM, et al. Attained Educational Level and Incident Atherothrombotic Events in Low- and Middle-Income Compared With High-Income Countries. Circulation. 2010 Sep 21;122(12):1167-75.

10. Rosengren A, Smyth A, Rangarajan S, Ramasundarahettige C, Bangdiwala SI, AlHabib $\mathrm{KF}$, et al. Socioeconomic status and risk of cardiovascular disease in 20 low-income, middle-income, and high-income countries: the Prospective Urban Rural Epidemiologic (PURE) study. Lancet Glob Health. 2019 Jun 1;7(6):e748-60.

11. Ribeiro Antonio Luiz P., Duncan Bruce B., Brant Luisa C. C., Lotufo Paulo A., Mill José Geraldo, Barreto Sandhi M. Cardiovascular Health in Brazil. Circulation. 2016 Jan 26;133(4):422-33.

12. Ministério da Saúde. DATASUS [Internet]. [cited 2018 Dec 3]. Available from: http://www2.datasus.gov.br/DATASUS/index.php?area=0205

13. Instituto Brasileiro de Geografia e Estatistica. Portal do IBGE [Internet]. [cited 2020 Jan 16]. Available from: https://www.ibge.gov.br/

14. Lima EEC de, Queiroz BL. Evolution of the deaths registry system in Brazil: associations with changes in the mortality profile, under-registration of death counts, and ill-defined causes of death. Cad Saúde Pública. 2014 Aug;30(8):1721-30. 
15. França EB, Passos VM de A, Malta DC, Duncan BB, Ribeiro ALP, Guimarães MDC, et al. Cause-specific mortality for 249 causes in Brazil and states during 1990-2015: a systematic analysis for the global burden of disease study 2015. Popul Health Metr. 2017 Nov 22;15(1):39.

16. Harper S, Lynch J, Smith GD. Social Determinants and the Decline of Cardiovascular Diseases: Understanding the Links. Annu Rev Public Health. 2011;32(1):39-69.

17. Galobardes B, Shaw M, Lawlor DA, Lynch JW, Smith GD. Indicators of socioeconomic position (part 1). J Epidemiol Community Health. 2006 Jan 1;60(1):7-12.

18. Borges G. Improving mortality estimates from household deaths reported in censuses (Extended Abstract). In: Population Association of America 2017 Annual Meeting [Internet]. 2017 [cited 2020 Jan 15]. p. P1-18. Available from: https://paa.confex.com/paa/2017/mediafile/ExtendedAbstract/Paper11265/Extended_A bstractPAA_Final.pdf

19. Mary Schooling C, Lau EWL, Tin KYK, Leung GM. Social disparities and cause-specific mortality during economic development. Soc Sci Med. 2010 May 1;70(10):1550-7.

20. Khan JA, Trujillo AJ, Ahmed S, Siddiquee AT, Alam N, Mirelman AJ, et al. Distribution of chronic disease mortality and deterioration in household socioeconomic status in rural Bangladesh: an analysis over a 24-year period. Int J Epidemiol. 2015 Dec 1;44(6):1917-26.

21. Hosseinpoor AR, Parker LA, d'Espaignet ET, Chatterji S. Socioeconomic Inequality in Smoking in Low-Income and Middle-Income Countries: Results from the World Health Survey. PLOS ONE. 2012 Aug 29;7(8):e42843.

22. Pampel FC, Denney JT, Krueger PM. Obesity, SES, and economic development: A test of the reversal hypothesis. Soc Sci Med 1982. 2012 Apr;74(7):1073-81.

23. Luhar S, Mallinson PAC, Clarke L, Kinra S. Trends in the socioeconomic patterning of overweight/obesity in India: a repeated cross-sectional study using nationally representative data. BMJ Open [Internet]. 2018 Dec 1 [cited 2020 Jan 16];8(10). Available from: https://bmjopen.bmj.com/content/8/10/e023935

24. Monteiro CA, Conde WL, Popkin BM. Income-Specific Trends in Obesity in Brazil: 1975-2003. Am J Public Health. 2007 Oct 1;97(10):1808-12.

25. Subramanian SV, Corsi DJ, Subramanyam MA, Smith GD. Jumping the gun: the problematic discourse on socioeconomic status and cardiovascular health in India. Int $J$ Epidemiol. 2013 Oct;42(5):1410-26.

26. Rasella D, Harhay MO, Pamponet ML, Aquino R, Barreto ML. Impact of primary health care on mortality from heart and cerebrovascular diseases in Brazil: a nationwide analysis of longitudinal data. The BMJ [Internet]. 2014 Jul 3 [cited 2019 Jan 3];349. Available from: https://www.ncbi.nIm.nih.gov/pmc/articles/PMC4080829/

27. Cavalini LT, Ponce de Leon ACM. Correção de sub-registros de óbitos e proporção de internações por causas mal definidas. Rev Saúde Pública. 2007 Feb;41(1):85-93.

28. França E, Teixeira R, Ishitani L, Duncan BB, Cortez-Escalante JJ, de Morais OL, et al. III-defined causes of death in Brazil: a redistribution method based on the investigation of such causes. Rev Saúde Pública. 2014 Aug;48(4):671-81. 
29. Hosseinpoor AR, Bergen N, Mendis S, Harper S, Verdes E, Kunst A, et al. Socioeconomic inequality in the prevalence of noncommunicable diseases in low- and middle-income countries: Results from the World Health Survey. BMC Public Health. 2012 Jun 22;12(1):474.

30. Valkonen T. Problems in the measurement and international comparison of socioeconomic differences in mortality. Soc Sci Med. 1993 Feb 1;36(4):409-18. 


\section{FIGURE LEGENDS}

Figure 1: Rate ratios for association between education (<8 vs $8+$ years) and cardiovascular mortality by quintile of state Human Development Index in Brazil, 2010. HDI=Human Development Index, CVD=Cardiovascular disease, IHD=Ischaemic heart disease 


\section{TABLES}

Table 1: Description of the included sample and age-adjusted associations between education and cardiovascular mortality in Brazil, 2010

\begin{tabular}{|c|c|c|c|c|c|c|c|c|c|c|}
\hline & \multirow{2}{*}{$\begin{array}{c}n \\
(\mathrm{~N}=62,568,055)\end{array}$} & \multicolumn{3}{|c|}{ Number of deaths in $2010^{a}$} & \multicolumn{3}{|c|}{$\begin{array}{l}\text { Crude mortality rate per } \\
\qquad 100,000\end{array}$} & \multicolumn{3}{|c|}{$\begin{array}{l}\text { Age-adjusted rate ratio for }<8 \text { vs } 8+\text { years } \\
\text { education }(95 \% \mathrm{Cl})\end{array}$} \\
\hline & & CVD & $\mathrm{IHD}$ & Stroke & CVD & IHD & Stroke & CVD & IHD & Stroke \\
\hline \multicolumn{11}{|l|}{ Women } \\
\hline All & $32,899,916$ & 89,392 & 23,692 & 25,526 & 271.7 & 72.0 & 77.6 & & & \\
\hline $\begin{array}{l}8+\text { years } \\
\text { education }\end{array}$ & $20,615,737$ & 14,443 & 4,564 & 3,906 & 70.1 & 22.1 & 18.9 & 1 & 1 & 1 \\
\hline $\begin{array}{l}<8 \text { years } \\
\text { education }\end{array}$ & $12,284,179$ & 74,949 & 19,128 & 21,619 & 610.1 & 155.7 & 176.0 & $\begin{array}{l}2.93 \\
(2.85,3.01)\end{array}$ & $\begin{array}{l}2.54 \\
(2.45,2.64)\end{array}$ & $\begin{array}{l}3.02 \\
(2.88,3.17)\end{array}$ \\
\hline \multicolumn{11}{|l|}{ Men } \\
\hline All & $29,668,139$ & 95,991 & 31,876 & 25,322 & 323.5 & 107.4 & 85.4 & & & \\
\hline $\begin{array}{l}8+\text { years } \\
\text { education }\end{array}$ & $17,999,163$ & 21,921 & 9,058 & 4,894 & 121.8 & 50.3 & 27.2 & 1 & 1 & 1 \\
\hline $\begin{array}{l}<8 \text { years } \\
\text { education }\end{array}$ & $11,668,976$ & 74,070 & 22,818 & 20,427 & 634.8 & 195.5 & 175.1 & $\begin{array}{l}2.21 \\
(2.17,2.25)\end{array}$ & $\begin{array}{l}1.78 \\
(1.72,1.84)\end{array}$ & $\begin{array}{l}2.63 \\
(2.53,2.73)\end{array}$ \\
\hline
\end{tabular}

$\mathrm{CVD}=$ Cardiovascular disease, $\mathrm{IHD}=$ Ischaemic heart disease, $\mathrm{Cl}=$ Confidence interval

${ }^{\mathrm{a}}$ Death numbers are averaged across the 5 imputed datasets. 
Table 2: Associations between education and cardiovascular mortality stratified by quintile of state-level Human Development Index in Brazil, 2010

\begin{tabular}{|c|c|c|c|c|c|c|c|c|}
\hline & \multicolumn{5}{|c|}{$\begin{array}{c}\text { Age-adjusted rate ratio for having }<8 \text { vs } 8+\text { years education }(95 \% \mathrm{Cl}) \\
\text { by quintile of state } \mathrm{HDI}\end{array}$} & \multirow{2}{*}{$\begin{array}{c}P- \\
\text { trend } \\
\text { by } \\
\text { quintile }\end{array}$} & \multirow{2}{*}{$\begin{array}{c}\text { Change in log rate } \\
\text { ratio per } 0.1 \text { unit } \\
\text { change in state } \mathrm{HDI} \\
(95 \% \mathrm{Cl})\end{array}$} & \multirow{2}{*}{$\begin{array}{l}P \text { - linear } \\
\text { trend }\end{array}$} \\
\hline & 1 (lowest) & 2 & 3 & 4 & 5 (highest) & & & \\
\hline \multicolumn{9}{|c|}{ Women, all ages } \\
\hline CVD & $3.75(3.29$, & $3.15(2.96,3.35)$ & $2.86(2.63,3.12)$ & $2.99(2.65,3.37)$ & 2.8 & 0.005 & $-0.18(-0.28,-0.07)$ & 0.002 \\
\hline IHD & $3.34(2.65,4.21)$ & $2.95(2.61,3.34)$ & $2.45(2.12,2.83)$ & $2.84(2.47,3.28)$ & $2.40(2.29,2.51)$ & 0.188 & $-0.12(-0.29,0.05)$ & 0.182 \\
\hline Stroke & $3.91(3.17,4.81)$ & $3.04(2.71,3.42)$ & $3.04(2.61,3.54)$ & $3.12(2.75,3.54)$ & $2.93(2.77,3.10)$ & 0.177 & $-0.13(-0.32,0.05)$ & 0.164 \\
\hline \multicolumn{9}{|c|}{ Men, all ages } \\
\hline CVD & $2.53(2.32,2.77)$ & $2.24(2.12,3.37)$ & $1.93(1.80,2.07)$ & $2.14(1.97,2.31)$ & $2.26(2.20,2.31)$ & 0.568 & $-0.06(-0.15,0.04)$ & 0.258 \\
\hline IHD & $1.96(1.68,2.29)$ & $1.69(1.54,1.85)$ & $1.57(1.41,1.75)$ & $1.97(1.79,2.16)$ & $1.80(1.73,1.87)$ & 0.184 & $0.07(-0.08,0.23)$ & 0.334 \\
\hline Stroke & $2.97(2.46,3.59)$ & $2.57(2.32,2.85)$ & $2.55(2.21,2.94)$ & $2.63(2.36,2.94)$ & $2.67(2.54,2.80)$ & 0.765 & $-0.03(-0.21,0.14)$ & 0.713 \\
\hline \multicolumn{9}{|c|}{ Women, <70 } \\
\hline CVD & $4.34(3.7$ & $3.37(3.07,3.70)$ & $3.36(2.90,3.89)$ & $3.73(3.2$ & 3.34 & 0.042 & $-0.14(-0.26$, & 0.032 \\
\hline IHD & $4.52(3.24,6.31)$ & $3.41(2.78,4.18)$ & $2.67(2.16,3.32)$ & $3.50(2.89,4.24)$ & $2.80(2.6$ & 0.119 & $-0.16(-0.37,0.05)$ & 0.143 \\
\hline Stroke & $4.59(3.26,6.47)$ & $3.50(2.93,4.18)$ & $3.56(2.92,4.33)$ & $3.77(3.07,4.63)$ & $3.31(3.0$ & 0.293 & $-0.13(-0.33,0.08)$ & 0.222 \\
\hline \multicolumn{9}{|c|}{ Men, $<70$} \\
\hline CVD & $2.88(2.55,3.24)$ & $2.60(2.41,2.82)$ & $2.58(2.33,2.86)$ & $2.64(2.42,2.89)$ & $2.91(2.83,2.99)$ & 0.651 & $0.04(-0.08,0.15)$ & 0.545 \\
\hline IHD & $2.29(1.91,2.76)$ & $1.90(1.70,2.13)$ & $1.88(1.62,2.17)$ & $2.22(1.95,2.52)$ & $2.11(2.01,2.21)$ & 0.316 & $0.07(-0.10,0.24)$ & 0.414 \\
\hline Stroke & $3.16(2.37,4.22)$ & $2.97(2.55,3.45)$ & $3.03(2.55,3.61)$ & $3.32(2.81,3.93)$ & $3.15(2.95,3.37)$ & 0.584 & $0.06(-0.14,0.25)$ & 0.552 \\
\hline
\end{tabular}

$\mathrm{Cl}=$ confidence interval, $\mathrm{HDI}=$ Human Development Index, $\mathrm{CVD}=$ Cardiovascular disease, IHD=Ischaemic heart disease 